\title{
Improving emotive communication: verbal, prosodic and kinesic conflict- avoidance techniques
}

\section{Horst Arndt and Richard W. Janney}

\begin{abstract}
Industrial language programme developers who wish to improve emotive communication and reduce supervisor-worker conflicts can profit from recent research by interactional psychologists, social psychologists and investigators of nonverbal communication. Three emotive aspects of speech are central to conflict-avoidance: levels of assertiveness, interpersonal involvement and emotional intensity. In face-to-face speech these are signalled by various verbal, vocal and kinesic activities. Conflict-avoidance is largely a matter of impression management. A supervisor who wishes to avoid unnecessary conflicts actively maintains a supportive communicative environment. When delivering positive messages he is assertive, interpersonally involved, and more emotional than usual. When delivering negative messages he is relatively nonassertive, impersonal and unemotional. Multimodal techniques for avoiding conflicts in various industrial settings are discussed in the paper.
\end{abstract}

Die samestellers van industriële taalprogramme wat daarna mik om emotiewe kommunikasie te verbeter en om opsiener/werker-konflik te verminder, sal baat vind by resente navorsing deur interaksie-psigoloë, sosiale psigoloë en ondersoekers na nie-verbale kommunikasie. Drie emotiewe aspekte van spraak staan sentraal in die vermyding van konflik: vlakke van selfgelding, interpersoonlike betrokkenheid en emosionele intensiteit. In gesprekke van aangesig tot aangesig word hierdie aspekte oorgedra deur verskeie verbale, vokale en kinestetiese aktiwiteite. Om konflik te vermy hang in 'n groot mate saam met die skep van 'n positiewe indruk. 'n Opsiener wat graag onnodige konflik wil vermy, skep op aktiewe wyse 'n ondersteunende kommunikatiewe omgewing. Wanneer hy positiewe boodskappe oordra, doen hy dit met gesag, hy is interpersoonlik betrokke en meer emosioneel as gewoonlik. Met die oordra van negatiewe boodskappe is hy relatief onaanmatigend, onpersoonlik en onemosioneel. Multi-modale tegnieke vir die vermyding van konflik in verskeie industriële opsette word in hierdie artikel bespreek.

\section{Introduction}

In a recent paper on industrial language training in South Africa, van der Vyver, Engelbrecht and Gxilishe (1983) point out the importance of effective communication at the supervisor-worker level. Ineffective communication here, they say, causes safety hazards, accidents, unnecessary delays, labour disputes, misunderstandings and resentment . In the following paper we focus on the problem of reducing supervisor-worker conflicts. We restrict our discussion to a relatively small part of a very large and important aspect of speech: emotive communication, or the communication of momentary attitudes, feelings and other affective states. This, we believe, is a domain of primary relevance for reducing supervisor-worker conflicts, and research in this domain has important implications for the development of industrial language training programmes in South Africa.

We single out emotive communication here as a 
key to reducing conflicts because it has received considerable attention by social psychologists and investigators of face-to-face communication, and because it can be approached more systematically from our point of view than some other subjects. Being non-South Africans, we lack experience in the ethnolinguistics, socio-cultural, political and other practical problems of language training in South Africa. Ultimately, research in these areas must be conducted by qualified, multi-lingual South African research tcams with the necessary insight, experience and $s$ nsitivity to the complexity of the issues involved (Gxilishe and Janney 1980).

Studies of face-to-face speech show that emotive communication involves a variety of verbal, prosodic and kinesic activities (Andt and Janney 1983; 1984a; Arndt, Janney and Pesch 1984). Research during the past few decades suggests the interpretation of spoken utterances depends to a large extent on accompanying nonverbal displays: e.g. vocal gestures, facial expressions, gazing patterns and so on (Arndt, Janney and Pesch 1984). Nonverbal cues play an important role in establishing the emotive contexts in which utterances are interpreted. The basic emotive dimensions of speech have been given considerable attention by clinical and social psychologists (Plutchik and Kellerman 1980; Arndt and Janney 1984b). The interpretation of verbal, prosodic and kinesic emotive cues has been studied extensively by investigators of nonverbal communication (Key 1975; Arndt, Janney and Pesch 1984). It appears that emotive communication can be described systematically, and models of cross-modal emotive expression can be developed (Arndt and Janney 1985).

According to interactional psychologists, one of the keys to avoiding interpersonal conflicts is supportive behaviour (Berger and Calabrese 1975; Brown and Levinson 1978; Bradac, Bowers and Courtright 1980). Supportive behaviour reduces emotional uncertainty, one of the main causes of aggresiveness and anxiety (i.e. fight/flight reactions). In the following pages we suggest the possibility of teaching supervisors communicative techniques which can reduce workers' emotional insecurity. The basic idea is that there are supportive and nonsupportive ways of expressing positive and negative feelings. The effective supervisor generally attempts to minimize the worker's emo- tional uncertainty by being as supportive as the situation allows. The point is not to refrain from being critical or to abdicate authority by becoming the worker's friend, but to learn how to perform normal supervisional tasks (giving orders, instructions, explanations, evaluations, etc.) without causing unnecessary interpersonal friction.

\section{Basic issues in avoiding conflicts}

It is helpful to begin with an overview of the basic issues involved in avoiding interpersonal conflicts. In any human relationship, conflicts arise when one partner feels his personal needs are being ignored or actively opposed by the other. Two types of needs are especially important in everyday interaction: (1) the need for autonomy (i:e. the desire to be unimpeded, free, self-determining) and (2) the need for acceptance (i.e. the desire to be approved of, respected, appreciated). In interạctional litèrature, these are viewed as complementary aspects of what Goffman (1967) and others call face, or the positive self-image that every person wishes to claim for himself (Brown and Levinson 1978). According to interactionalists, the desire to maintain face, and the fear of losing it, are human universals transcending all socio-cultural, ethnic, sexual, educational, economic, geographical and historical boundaries.

From a psychological point of view, these two needs are antithetical in certain respects. Personal autonomy is realized in social interaction often only at the price of lower interpersonal acceptance, and conversely, interpersonal acceptance is often purchased only at the price of lower personal autonomy. As a.result, the desire to be unimpeded by others and the desire for approval often conflict, leading to what psychologists since Bateson et al (1956) refer to as double bind situations. The essence of a double bind situation is a contradiction between mutually exclusive alternatives which forces the individual into something like a position of psychological checkmate (Laing 1967). Double binds are difficult to endure; people tend to gravitate toward one alternative or the other, altering their behaviour accordingly on a situation-to-situation basis, sometimes creating the impression of multiple personalities (Osgood and Luria 1954; Thigpen and Cleckley 1957) or multiple social roles (Firth 1964:67). 
From a socio-psychological perspective, it is nearly impossible to avoid double binds in everyday interaction. No matter how carefully one tries to avoid conflicts, every request, suggestion, directive or evaluation related to one's partner is a potential violation of the partner's personal territory and thus a potential threat to his positive self-image (Stiles 1978). Interpersonal conflicts are thus nascent in almost all communicative situations. Normal speakers are intuitively aware of this, and more or less subconsciously adopt speech strategies aimed at minimizing potential threats to their partner's face.

Much of what we call politeness is simply facesaving work (Arndt and Janney 1985). Speakers commonly smile when saying negative things to avoid threatening their partner's need for acceptance, e.g.

\section{(1) Why aren't you working (smiling)}

They become more indirect when making certain requests or commands to signal respect for their partner's autonomy, e.g.

\section{(2) Mary, have you got a minute}

They adopt less assertive intonations to soften the forcefulness of directives, e.g.

\section{(3) Don't come "late, Robert}

These and other techniques enable speakers to impose on others without threatening their "face": Generally, speakers who wish to avoid conflicts try to minimize personal territorial transgressions (i.e. grant others as much autonomy as the situation allows) and maximize signs of interpersonal acceptance. In other words, they project a definition of the situation in which the partner is not forced to choose between mutually exclusive behavioural options such as agree/disagree, attack/defend, or obey/disobey.

This suggests an important potential conflict in all supervisor-worker relationships. Industrial situations are inherently double bind situations for both parties. The supervisor, due to his power over the workers and his responsibility for getting the job done, represents a more or less ongoing constraint on his workers' autonomy and is thus a threat to this aspect of their face. Every order impinges on the workers' freedom in some way. The workers, by the same token, because they may either cooperate with the supervisor or work covertly against him, also represent a potential threat to the supervisor's face. For this reason, the supervisorworker relationship is always ambivalent to some extent, and needs continuously to be ratified and renegotiated in response to potential face threats and the emotional double binds caused by these (Berger and Calabrese 1975; Berger 1979). How the supervisor handles his workers interpersonally thus becomes very important. Both his success in getting the immediate job performed and his success in supervising subsequent jobs depend on how he handles his workers on a case-to-case, momentto-moment basis. In countries such. as South Africa, where supervisors and workers often share no native language or culture, interpersonal problems of this sort may become endemic, and the difficulties resulting from these, manifold. Linguistic and intercultural misunderstandings (Arndt and Janney 1984b) may further limit the supervisor's alternatives for avoiding conflicts.

In order to suggest practical solutions to these problems, it is necessary to introduce a few more basic ideas about interpersonal communication, and to discuss how these might be integrated into present industrial language training programmes with a view towards conflict-avoidance. In the remaining sections we sketch out a minimal framework for such an attempt. It is rooted in our research and reflections on face-to-face speech during the past eight years; parts of it are adapted from a book-length -manuscript entitled InterGrammar: theory, research and data for a multimodal model of verbal, prosodic and kinesic choices in speech which is currently nearing completion in Cologne.

\section{Impression management}

We may assume that a supervisor's communicative intentions in everyday practice can be reduced to a relatively restricted list of basic requests, orders, instructions, evaluative comments and so on, which recur regularly due to the nature of the tasks he supervises (Arndt and Janney 1981; 1983; 
Janney 1983). Some such assumption is implicit in all functionally-oriented industrial language training programmes; in South Africa, for instance, it is one of the assumptions behind Engelbrecht and Gxilishe's (1983) Xhosa for Industry, to which we shall return later. In addition, we may assume the supervisor-at least in his own native language, when talking to members of his own culture-is intuitively able to express any of these intentions in various ways. How he expresses these depends on one of two cognitive-emotive factors: (1) how he actually feels at the mom $\geq$ nt (i.e. his actual affective state), or (2) how he wants his partner to believe he feels at the moment (i.e. a projected affective state).

The communication of both actual and projected affective states is important in everyday interaction, the latter especially, for this is what enables people to avoid direct confrontations. A certain degree of emotive projecting, or what we might call impression management (Patterson 1983:111-12), is absolutely necessary for smooth interaction. For instance, saying "yes" (verbally) and implying "no" (vocally, kinesically) is a standard means of avoiding hurting people's feelings. There is nothing hypocritical about it; it is merely one of the communicative techniques learned by all normal native speakers which enables them to interact with other members of their culture without getting into unnecessary emotional difficulties. It is a technique similar to formulating commands (come here) as neutral questions (have you got a minute), as in example (2) above; the difference is that it is a multimodal technique in which nonverbal cues contradict or modify verbal cues (Arndt, Janney and Pesch 1984).

Impression management, we shall say, is the verbal, vocal and/or kinesic projection of a certain definition of the situation for the listener's benefit. There seems to be an unspoken agreement among speakers that one is held interpersonally responsible only for what one "intends" to say, and in cases where what literally is said is contradicted by how it is said, one is generally allowed to act as if the latter were unintentional. Informal agreements of this sort reduce double binds and protect people from face threats. They do not interfere with communication. In normal intracultural situations, the addressee of the verbal "yes" and nonverbal "no" understands the answer is negative, just as the addressee of the command phrased as a question recognizes the utterance is a directive. The important difference is that the messages, thus formulated, are not interpersonally threatening. This notion has important applications in industrial relations and it could be incorporated into present language training programmes with little difficulty. The point would be to provide employees with a basic stock of emotive communicative strategies for reaching different goals in different situations with a minimum of interpersonal friction.

Assertiveness, interpersonal involvement, and emotional intensity

Three aspects of speech are central to conflictavoidance: levels of (1) assertiveness, (2) interpersonal involvement, and (3) emotional intensity (Arndt and Janney 1985). In everyday practice these are complexly interrelated; we distinguish between them here purely conceptually, for purposes of discussing conflict-avoidance techniques. Every comment made by a supervisor to a worker is characterized by combinations of these, and how the supervisor modulates assertiveness, interpersonal involvement and emotional intensity when he speaks is important to impression management. Some of the verbal, vocal and kinesic characteristics of these are summarized below (for a more comprehensive discussion see Arndt, Janney and Pesch 1984; Arndt and Janney 1985; verbal tokens in English and Xhosa are from Engelbrecht and Gxilishe 1983).

\section{Assertiveness}

High levels of assertiveness are characterized by verbal directness and by references to the speaker in the subject position; there is a tendency to rely on falling pitch contours. Kinesically, assertiveness is often signalled by a full gaze or by higher than usual eye contact, e.g.
(4)
Ndikuthiyile ...
(full gaze)

I don't ‘like that

Lower levels of assertiveness are characterized by less verbal directness and by more emphasis on the listener; there is a tendency to shift to a rising or 
falling-rising intonation in English, and of eye contact lower, e.g.

$$
\text { Can you " come }
$$

Ungafika ...

(averted gaze)

Assertiveness may be understood here in the sense of self-confidence or self assertiveness (Russell 1978). The more assertively a supervisor expresses himself, the fewer alternatives he leaves for the worker to respond. Levels of assertiveness are important in the negotiation of personal autonomy.

\section{Interpersonal involvement}

High levels of interpersonal involvement are characterized by first person references to the listener, or by inclusive references to the speaker and listener, and by increased facial gesturing, e.g.

Tolo, we've received an 'order

Tolo sifumene iodolo (smiling)

or

$$
\text { Tolo, what shall we`do }
$$

Tolo siza kwenza ntoni

(frowning)

Lower levels of interpersonal involvement are characterized by the omission of references to the speaker and listener, and by reduced facial activity, e.g.

(8)

What "happened

Bekutheni

(unsmiling)

or

Why is there still 'grease here

Kutheni kúsekho igrisi ...

(unsmiling)

The more positive interpersonal involvement the supervisor signals to the worker, the greater the compensation for impositions on the worker's personal autonomy. This is why signals of interperson- al involvement are important in preserving workers' face and avoiding conflicts.

\section{Emotional intensity}

High levels of emotional intensity are characterized by emotionally-laden language, extreme pitch nucleus prominence, and noticeable increases of body tension, e.g.

Damn it! I don't 'want that

Nx! Andiyifuni loo nto

(tense)

Lower levels of emotional intensity are characterized by more emotionally neutral language, normal pitch nucleus prominence, and a relaxed body posture, e.g.

Some of you came 'late this week. All those who came on time will receive a 'bonus. All those who came late will 'not.

(relaxed)

Abanye benu bafike emva kwexesha kule veki. Bonke abafike ngexesha baza kufumana ibhonasi. Bonke abafike emva kwexesha abazi kuyifumana.

Emotional intensity, whether positive or negative, amplifies signals of self-assertiveness and/or interpersonal involvement. For this reason it also figures importantly in conflict-avoidance.

\section{A schema of emotive cues}

These characteristics of assertiveness, interpersonal involvement and emotional intensity are represented in Table 1 on page 26 . The table suggests a few dimensions of emotive communication relevant to the present discussion. Obviously there are more, but we restrict ourselves to these for the sake of simplicity. In the following section we turn to the notion of supportiveness, illustrating the interaction between verbal, vocal and kinesic emotive cues in different positive and negative industrial speaking situations. 


Verbal Prosodic Kinesic

\section{Asssertiveness}

\begin{tabular}{llll} 
High & $\begin{array}{l}\text { highly explicit } \\
\text { "I" oriented } \\
\text { less explicit } \\
\text { "you" oriented }\end{array}$ & $\begin{array}{l}\text { falling intonation } \\
\text { rising or falling-rising } \\
\text { intonation }\end{array}$ & low eye contact \\
\hline
\end{tabular}

\section{Interpersonal} involvement

\begin{tabular}{lll} 
High & $\begin{array}{l}\text { first-person references } \\
\text { to listener, } \\
\text { "we" oriented } \\
\text { no personal references }\end{array}$ & $\begin{array}{l}\text { increased facial gesturing } \\
\text { (e.g. smiling/frowning) }\end{array}$ \\
Low & little or nó facial gesturing \\
\hline
\end{tabular}

\section{Emotional intensity}

\begin{tabular}{|c|c|c|c|}
\hline High & $\begin{array}{l}\text { emphatically value- } \\
\text { laden language }\end{array}$ & $\begin{array}{l}\text { high pitch nucleus } \\
\text { prominence }\end{array}$ & increased physical tension \\
\hline Low: & $\begin{array}{l}\text { emotionally neutral } \\
\text { language }\end{array}$ & $\begin{array}{l}\text { normal pitch nucleus } \\
\text { prominence }\end{array}$ & $\begin{array}{l}\text { little or no physical } \\
\text { tension }\end{array}$ \\
\hline
\end{tabular}

Table 1: Verbal, prosodic and kinesic emotive cues

\section{The dynamics of positive and negative messages}

Earlier we suggested a key to avoiding interpersonal conflicts is supportiveness, the protection of one's partner's face. In the industrial connection, a supportive supervisor smooths over uncomfortable situations, or keeps delicate situations from becoming interpersonally threatening, by acknowledging the worker's intrinsic worth as a person. He does this by verbally, prosodically and kinesically confirming the worker's claim to a positive selfimage.

Recent work by interactional psychologists and others provides some insight into the communicative techniques by which this is done (Berger and Calabrese 1975; Brown and Levinson 1978; Stiles 1978; Berger 1979; Bradac, Bowers and Courtright 1979,1980 ). The basic notion is that speakers' strategies for avoiding conflicts vary depending on whether their messages are presumed to have positive or negative implications for their partners. According to Bradac, Bowers and Courtright (1980), positive messages have to be formulated assertively and accompanied by nonverbal displays of assertiveness, interpersonal involvement and a certain degree of emotional involvement in order to avoid creating the impression that they are not positive enough (i.e: covert threats to face). Conversely, negative messages have to be formulated nonassertively and accompanied by nonverbal displays of nonassertiveness, interpersondl uninvolvement and emotional uninvolvenent in order to avoid creating the impression that they are too negative (i.e. overt threats to face).

This notion has some potentially interesting applications in industrial situations, where it is relatively easy to differentiate among messages which may be presumed to have positive implications for workers (e.g. compliment, appreciation, apology, permission, gratitude, agreement) and messages which may be presumed to have negative implications (e.g. criticism, reprimand, command, refusal, disagreement). The idea would be to give supervisors a simple framework of strategies for effective emotive communication somewhat like Table 2, together with the appropriate utterances and nonverbal cues for putting these into practice in the target language. 
Implication of the message for worker

positive

$$
\text { Supervisor's strategies Emotive goals }
$$

associate worker positively with self and topic

$$
\text { interpersonalize }
$$

associate self with topic
Appropriate techniques

refer to worker by name, and to self

smile

\begin{tabular}{ll} 
be assertive & $\begin{array}{l}\text { associate self } \\
\text { with topic }\end{array}$ \\
\hline emotionalize & $\begin{array}{l}\text { associate feelings } \\
\text { with topic }\end{array}$
\end{tabular}

be explicit

use falling intonation

maintain high eye contact laden language use emphatically positive-

use more vocal stress than usual

$\begin{array}{ll}\text { impersonalize } & \begin{array}{l}\text { dissociate worker } \\ \text { from self and topic }\end{array}\end{array}$

from self and topic

avoid referring directly to self or worker

avoid a negative facial expression

\begin{tabular}{lll}
\hline be nonassertive & $\begin{array}{l}\text { dissociate self } \\
\text { from topic }\end{array}$ & $\begin{array}{l}\text { avoid bluntness } \\
\text { use rising or falling-rising } \\
\text { intonation } \\
\text { avoid unusually high eye } \\
\text { contact }\end{array}$ \\
\hline de-emotionalize & $\begin{array}{l}\text { dissociate strong } \\
\text { feelings from topic }\end{array}$ & $\begin{array}{l}\text { avoid strongly value- } \\
\text { laden language } \\
\text { use normal vocal stress } \\
\text { remain relaxed }\end{array}$ \\
\hline
\end{tabular}

Table 2: Techniques for communicating positive and negative messages

With a minimal framework such as this, language programme developers in South Africa and elsewhere might begin the important task of discovering the appropriate techniques for avoiding conflicts in the languages they wish to teach. Research on emotive communication among speakers of Xhosa, Zulu, Sotho and other native South African languages would probably. lead to changes in the last column of Table 2, which is based on what we know about English emotive communication. It is not yet clear in how far assumptions about conflictavoidance among members of Western cultures may be applied to non-Western or mixed cultural situations (Gxilishe and Janney 1980). Nevertheless, the framework itself, and the interactional psychological principles upon which it is based, retain their validity and may be used to systematize the search for intercultural conflict-avoidance techniques. Once these are discovered it should prove relatively easy to integrate them into industrial language training programmes. In the following section we suggest how conflict-avoidance techniques could complement a training programme such as Engelbrechit and Gxilishe's (1983) introductory Xhosa course. Our examples are English; corresponding Xhosa techniques remain to be discovered.

\section{Industrial conflict-avoidance techniques}

Before beginning, it is necessary to point out two features of industrial situations which may restrict a supervisor's ability to avoid conflicts in everyday 
practice. The first, which is a feature of mixed cultural interaction generally (Arndt and Janney 1984b), has already been mentioned, namely, the lack of a common native language. A supervisor and worker who share a common native language have more linguistic techniques available for avoiding conflicts than do speakers of different native languages. Among native speakers, potential confrontations are often avoided by verbal indirectness. A supervisor giving an order, for instance, has a variety of alternatives, e.g.

(12) Sweep here

(13) Will you sweep this up, please

(14) Bob, suppose you could do something about this trash here

(15) Bob, it's awfully dirty here

The more directly he gives his order, the more commanding it is; the less directly he gives it, the more requestive it becomes (vocal and kinesic factors aside). If the supervisor wishes to avoid conflicts, he refrains from directly ordering the worker to sweep up; he formulates his directive more in the style of (14) or (15). In effect, the indirectness is an interpersonal gesture recognizing the worker's intelligence and granting him a sense of responsibility. Such commands, from a facesaving point of view, are easier for the worker to follow than (12), for they allow him to define the situation in a way which preserves his dignity. Where supervisors and workers do not share a common native language, this type of interpersonal gesture is often difficult to perform, or when performed, it may be interpreted differently than intended. The same is true of many vocal and kinesic signs of indirectness.

The second feature of industrial situations that sometimes restricts the use of conflict-avoidance techniques has been discussed by Goffman (1981) under the term frame. In some contexts, the supervisor and worker may simply have no time for facesaving or other interpersonal considerations. This is true where noise, for example, interferes with communication, e.g.

the supervisor and worker are standing by a loud air hammer; the supervisor wants the worker to unload some bricks in a certain place and shouts
(16) 'Here (pointing to the place)

or in emergency situations, e.g.

the supervisor sees a crane operator about to lower a heavy steel beam into a hole where another worker is standing, and shouts the command

\section{(17) 'Stop (frowning) (tense)}

or in certain repetitive situations. where commands are a routine part of the task at hand, e.g.

the supervisor has been calling for cement slabs all day, notices it is time for more slabs again, and calls to the worker responsible for bringing them (18) More slabs (unsmiling)

For illustrative purposes, in the following pages we assume these restrictions on emotive communication do not play an important role in conflictavoidance. We assume both parties have a degree of proficiency in the language and the nonverbal cues used to illustrate our points, and that the supervisor and worker are communicating outside the frames mentioned above.

A supervisor, we shall suggest, should have at least two types of alternatives for saying any of the routine things required in his evetyday life with his workers: (1) what we have called supportive alternatives, which minimize intrusions into the workers' private territory, acknowledge their needs for autonomy and acceptance, and protect them from losing face, and (2) nonsupportive alternatives which do not do these things, for situations where it is important to assert authority, establish distance from the workers, or signal for whatever reason that the supervisor is not interested in being considerate. The former alternatives are important in avoiding conflicts, the latter, in maintaining discipline. Contrasts are kept as sharp as possible below to illustrate the differences between supportiveness and nonsupportiveness (for the discussion of "neutral" or "common core" utterances, see Arndt and Janney 1981a, 1983).

\section{Requests for information}

In everyday nonintimate speech, the person who requests information is at an interpersonal disad- 
vantage; he wants something (the information) from his partner, and because the partner may or may not give this to him, he tends to formulate his request multimodally in such a way as to minimize the intrusion and maximise friendly relations. For an industrial supervisor, however, the dynamics of simple requests are somewhat different. Due to his power over the worker he has little reason to suspect he will not receive the desired information, and thus he is often little motivated to show conventional consideration for his partner's face needs. From a worker's perspective, there is little functional difference between a supervisor's requests and commands; nevertheless, a request formulated supportively, e.g.

(20) Tolo, do you know what 'happened (normal gaze) (smiling) (relaxed)

has a different interpersonal impact than one formulated unsupportively, e.g.

$$
\begin{aligned}
& \text { (21) What 'happened (full gaze) (frowning) } \\
& \text { (tense) }
\end{aligned}
$$

A supportive request for information recognizes the worker's need for acceptance and autonomy; it contains positive interpersonal involvement cues and is relatively nonassertive and de-emotionalized. It does not change the supervisor-worker relationship; rather, it defines the situation as an unthreatening one for the worker.

\section{Commands}

The most usual way of issuing commands supportively is to formulate them as requests. The object of this communicative strategy in industrial settings is not to diminish the authority of the person making the command, but to signal acceptance of the person receiving it. As Hoover (1977) points out in his remarks on developing supportive climates, acceptance of the workers' attitudes without debate-which also implies taking their face needs seriously-is the essence of supportiveness. A supportive climate naturally leads to what he calls a mutual-stake orientation among subordinates (Hoover 1977:14). A supervisor concerned with developing such an interpersonal climate should thus use relatively nonassertive request forms for orders, e.g.
(22) Tolo, can you load these 'boxes, please (normal gaze)

in place of assertive imperatives, e.g.

(23) Load these 'boxes (full gaze)

Wherever possible, he should appeal to group solidarity, e.g.

(24) Now we've got to clean 'up here, Tolo (smiling)

rather than appealing to his own authority, e.g.

(25) I want you to clean up here now (unsmiling)

When giving particularly unpopular commands, he should impersonalize and de-emotionalize them, e.g.

(26) All the cement slabs have to be carried over there (normal gaze) (unsmiling) (relaxed)

rather than associating himself or the worker with them directly, e.g.

(27) You will carry all the cement slabs over there (full gaze) (unsmiling) (tense)

The basic idea, from an impression management point of view, is to refrain wherever possible from defining negative situations for the worker in unavoidably negative terms.

\section{Expressions of approval}

Earlier we pointed out that according to interactional studies (Bradac, Bowers and Courtright 1980), certain levels of involvement, assertiveness and emotionality are expected in conjunction with positive utterances; if these emotive cues are not present, or if they are not sufficiently emphatic, native speakers tend to interpret positive utterances as ironic, insincere or sarcastic (Arndt and Janney 1984a, 1985). It remains to be discovered in how far this notion is valid in interaction between speakers of different native languages. Nevertheless, a supervisor who wishes to avoid being misunderstood when expressing approval should inter- 
personalize, be assertive, and emotionalize the topic for the worker, e.g.

(28) Tolo, I'm 'very happy with your work (full gaze) (smiling)

rather than expressing approval aloofly, indirectly, or negatively, e.g.

(29) Your work isn't 'bad (averted gaze) (unsmiling)

\section{Expressions of disapproval}

In conjunction with negative utterances, high levels of interpersonal involvement, assertiveness and emotionality should be avoided. All forms of emphatic behaviour in negative utterances are susceptible to aggressive or hostile interpretations (Arndt and Janney 1980). For this reason, a supervisor who wishes to avoid conflicts should formulate expressions of disapproval as impersonally, nonassertively and unemotionally as possible, e.g.

(30) This was supposed to be finished an hour ago, wasn't it (normal gaze) (smiling) (relaxed)

rather than expressing his disapproval emphatically or intimately, e.g.

(31) Damn it Tolo, why aren't you 'finished (full gaze) (frowning) (tense)

Again, a supportive supervisor has an active interest in preserving positive relations in his crew; a positive working climate is one where the workers do not feel threatened, and where their face needs are respected as much as the situation allows. There are obvious limits to supportiveness, just as there are obvious limits to nonsupportiveness. Ultimately, neither alone is sufficient for a productive supervisor-worker relationship; this is why we stress the importance of giving supervisors both types of communicative alternatives.

\section{Offers of help}

In everyday speech, the person who offers help or advice is at an interpersonal advantage; his partner needs something (help) from him. Conventionally, a speaker who wishes to offer assistance tends to formulate his offer in such a way as to minimize his partner's potential loss of face. This is done by defining the situation as unthreateningly as possible for the partner and by implying he may not need any help. In industrial situations, the fact that the supervisor normally decides who needs help makes his position as offerer somewhat different than that of the everyday speaker. The worker knows he has made a mistake when the supervisor wants to help him. For this reason, how the supervisor expresses this intention is important. He may define the situation as an unthreatening one, signalling his acceptance for the worker and being unassertive and unemotional, e.g.

(32) Tolo, should I show you how to 'do that (normal gaze) (smiling) (relaxed)

or he may define the situation as one where the worker has failed, signalling disdain and negative emotional involvement, e.g.

(33) You're doing that 'wrong, now 'listen to me (full gaze) (frowning) (tense)

Unthreatening strategies such as (32) help avoid conflicts; emotionally-laden strategies such as (33) invite conflicts.

\section{Requests for comprehension}

A similar pattern applies to requests for comprehension, which also may be supportive or nonsupportive. A supportive supervisor will give the worker an opportunity to say he has not understood an instruction without having to feel embarrassed or apprehensive, e.g.

(34) Would you like me to explain that 'again, Tolo (normal gaze) (smiling)

A nonsupportive supervisor will tend more to formulate his request like a command, defining noncomprehension for the worker as an act of disobedience, e.g.

(35) Do you `understand (full gaze) (unsmiling)

In the latter case, the worker finds himself in a classical double bind situation if he has not understood: if he tells the truth he may expect an angry 
response from his supervisor; if he lies he may expect to make some mistake which will also elicit an angry response from his supervisor. Unavoidably threatening situations such as this create emotional insecurity and lead to conflicts.

\section{Conversational openers}

The dynamics of help situations apply to almost all situations where the supervisor is in a position to co-operate or not to co-operate with a worker's wishes. One of these is where the supervisor is approached by a worker who wants to talk with him. A supportive supervisor will not put the worker's wish to talk in question, or threaten him in any way for wishing to talk. The supervisor will signal his readiness to get into a conversation by showing positive interpersonal involvement; he will be relatively unassertive and unemotional, e.g.

(36) 'Yes, Tolo (normal gaze) (smiling) (relaxed)

A nonsupportive supervisor will put the worker's wish to talk in question from the outset, signalling his disinterest or dislike by assertive negative interpersonal cues, e.g.

(37) What do you want (full gaze) (frowning) (tense)

\section{Granting and refusing permission}

Techniques for granting and refusing permission tend to follow the approval/disapproval pattern (see 6.3 and 6.4). A supportive supervisor will signal active readiness to comply with the worker's request, e.g.

(38) Of 'course you can go, Tolo (full gaze) (smiling)

A nonsupportive supervisor will signal interpersonal indifference, or formulate his permission as a command, implicitly separating the worker from the request, e.g.

(39) 'Go (averted gaze) (unsmiling)

When refusing permission, a supportive supervisor will either compensate for his refusal by showing positive involvement with the worker, e.g.

(40) 'Sorry, Tolo, but I need you 'here (full gaze) (smiling)

or he will appeal to solidarity and imply he and the worker are powerless in the situation, e.g.

(41) We all have to stay here until the 'orders are filled (normal gaze) (relaxed)

A nonsupportive supervisor will neither show involvement nor offer any reason for refusing permission, implicitly treating the worker like a nonentity, e.g.

(42) No (averted gaze) (unsmiling) (relaxed)

\section{Conclusion}

Hopefully, with these few examples we have made our point. Linguists interested in developing effective industrial language training programmes in South Africa and elsewhere can profit from work on face-to-face communication in such neighbouring disciplines as interactional psychology, social psychology and nonverbal communication research. With a relatively restricted list of emotive communicative cues, and a modest conceptual framework such as the one presented here, it is possible to approach conflict-avoidance systematically from a communications point of view. The approach lends itself well to functionally-oriented language training programmes, especially to those where role-taking and pattern drills are emphasized, as in Engelbrecht and Gxilishe's (1983) $X$ hosa for Industry. Conflict-avoidance techniques can be built into such courses with little difficulty, and the rewards in terms of improved emotive communication between supervisors and workers are potentially immediate.

Naturally we have suggested only theoretical solutions to the emotive communication problems discussed at the beginning of the paper (van der Vyver, Engelbrecht and Gxilishe 1983), or perhaps more accurately, only the preliminary thinking necessary for suggesting such solutions. This is usually the case when investigators of human communication try to deal with real human communication problems. Neither we nor the language programme developer who integrates the notions 
discussed here into an industrial language course may assume that this in itself will reduce supervisor-worker conflicts. As Key (1975), one of the pioneers in American nonverbal communication research, said more than a decade ago, most intercultural communication problems are not due to lack of understanding, but to lack of tolerance.

\section{Bibliography}

ARNDT, H. 1980. Linguistic issues in the assessment of attitudes and st reotypes. Niemeyer, $\mathrm{H}$. (ed.) Soziale Beziehungsgeflechte. Berlin: Duncker und Humbolt.

ARNDT, H. \& JANNEY, R.W. 1981. An interactional linguistic model of everyday conversational behavior. Die Neueren Sprachen 80(5).

- - - 1983. Towards an interactional grammar of spoken English. Morreall, J. (ed.) The Ninth LACUS Forum 1982. Columbia, SC: Hornbeam.

- - - 1984 (a). The duck-rabbit phenomenon: Notes on the disambiguation of ambiguous utterances. Enninger, W., Haynes, L. (eds.) Studies in Language Ecology. Wiesbaden: Steiner.

- - - 1984 (b). Interpersonal factors in intercultural (mis)understanding. Nagoya Gakuin University Round Table 10.

- - - - 1985 (forthcoming). Politeness revisited: Crossmodal supportive strategies. International Review of Applied Linguistics 23(4).

ARNDT, H., JANNEY, R.W. \& PESCH, H.W. 1984. Trimodale Interaktion: Grundlagen zur integrierten Interpretation von Sprache, Prosodie und Gestik. Die Neueren Sprachen 83(5).

BATESON, G. et al. 1956. Toward a theory of schizophrenia. Behavioral Sciences 1.

BERGER, C.R. 1979. Beyond initial interaction: Uncertainty, understanding and the development of interpersonal relations. Giles, H. \& St Clair, R.N. (eds.) Language and Social Psychology. Oxford: Blackwell.

BERGER, C.R. \& CALABRESE, R.J. 1975. Some explorations in initial interaction and be- yond: Toward a development theory of interpersonal communication. Human Communication Research 1.

BRADAC, J.J., BOWERS, J.W. \& COURTRIGHT, J.A. 1975. Three language variables in communication research: Intensity, immediacy, and diversity. Human Communication Research 5.

BRADAC, J.J., BOWERS, J.W. \& COURTRIGHT, J.A. 1980. Lexical variations in intensity, immediacy, and diversity: An axiomatic theory and causal model. St Clair, R.N. \& Giles, H. (eds.) The Social and Psychological Contexts of Language. Hillsdale, NJ: Erlbaum.

BROWN, P. \& LEVINSON, S. 1978. Universals in language usage: politeness phenomena. Goody, E.N. (ed.) Questions and Politeness. London: Cambridge University Press.

ENGELBRECHT, J.T. \& GXILISHE, D.S. 1983. Xhosa vir die Nywerheid: 'n beginnerskursus. Goodwood: Via Afrika.

FIRTH, J.R. 1964. On sociological linguistics. Hymes, D. (ed.) Language in Culture and Society. New York: Harper.

FOURIE, P.C. 1977. Goeie verhoudings tussen wit en swart werkers as grondslag vir verhoogde produktiwiteit. Business Management 8(1).

GXILISHE, D.S. \& JANNEY, R.W. 1980. Emphasis in TESL research development for South Africa. INTUS News 4.

GOFFMAN, E. 1967. Interactional ritual; essays on face-to-face behavior. Garden City, NY: Anchor.

- - - 1981. Forms of talk. Oxford: Blackwell.

HOOVER, D.J. 1977. Increasing human potential through communicative effectiveness. Supervisory Management 22(10).

JANNEY, R.W. 1983. Functional variation in English as an issue in TESL didactics. Neusprachliche Mitteilungen 36.

KEY, M.R. 1975. Paralanguage and Kinesics. Metuchen, NJ: Scarecrow Press. 
LAING, R.D. 1967. The politics of experience. Harmondsworth: Penguin.

OSGOOD, C.E. \& LURIA, Z. 1954. A blind analysis of a case of multiple personality using the Semantic Differential. Journal of Abnormal and Social Psychology 49.

PATTERSON, M.L. 1983. Nonverbal behavior: a functional perspective. New York: Springer.

PLUTCHIK, R. \& KELLERMAN, H. (eds.) 1980. Emotion: Theory, research and experience. New York, London: Academic Press.
RUSSEL, J.A. 1978. Evidence of convergent validity on the dimensions of affect. Journal of Personality and Social Psychology 36.

STILES, W.B. 1978. Verbal response modes and dimensions of interpersonal roles: A method of discourse analysis. Journal of Personality and Social Psychology 36(7).

THIGPEN, C.H. \& CHECKLEY, H.M. 1957. The three faces of Eve. New York: McGraw-Hill.

VAN DER VYVER, D.H., ENGELBRECHT, J.T. \& GXILISHE, D.S. 1983. The effect of language training on labour relations and productivity in industry. INTUS News 7(2).

The distance is nothing; it is only the first step which counts. (Remark on the legend that St Denis, carrying his head in his hands, walked two leagues.) 